\title{
FACE WORK SEORANG SPY DALAM GAME ONLINE SUPER ARMADA
}

\author{
Ami Saptiyono \\ Mahasiswa Program Studi Magister Ilmu Komuniaksi FISIP UNDIP Angkatan VIII \\ Email: ami.saptiyono.81@gmail.com
}

\begin{abstract}
Online media is media that provides a variety of facilities and services for people in activities and meet their needs. This media allows everyone to do various activities such as browsing , blogging, chat, update your status, upload and download data, and even play games . In this article, the researcher discuss how an online game players do face work in the activities of online gaming, especially in the game "Super Armada", through autoethnography methods, as a method of doing descriptions experience of researcher in this online game, using face work theory as reference in research
\end{abstract}

Key words: Face work, Autoethnography, Media online.

\section{PENDAHULUAN}

Perkembangan dunia online yang semakin pesat, membuat media ini memiliki fungsi yang semakin beragam, dengan fungsi hiburan sebagi salah satunya. Sebagai media hiburan, media online juga memiliki berbagai macam pilihan mulai dari film, musik, hingga permainan atau yang sering disebut sebagai Game Online.

Game Online, sebagai bentuk pengembangan media online, merupakan suatu sarana hiburan bagi seseorang melalui dunia maya. Menurut Nick Yee,Game Online dirilis pertama kali pada tahun 1996, yaitu Meridian 59 sebagai perkembangan dari MUD (Multy User Dungeon) yang merupakan multi player game pertama hasil karya dari Roy Trubshaw, mahasiswa Essex University pada tahun 1978. (Yee; 2014:13 -15)

Sebagai bentuk evolusi dari media online, Game Online juga memiiki fungsi sebagai edia bersosialisasi, sehingga di dalamnya terdapat fungsi - fungsi untuk bercakap - cakap, selayaknya Messenger atau chatting room, fitur berkirim email, sebagai sarana bagi para pemain untuk berinteraksi dengan pemain lainya.

Sebagai permainan yang interaktif, dapat diakses oleh banyak orang, dengan berbagai macam latar belakang politik, ekonomi, budaya, geografis, psikografis dan demografisnya, game online memiliki variasi pengguna (pemain) yang beragam.

Richard Bartle dalam yee menyatakan bahwa dalam Game Online, dapat dibedakan beberapa jenis pemain, yaitu:

a. Achievers, merupakan pemain yang mengejar prestasi dan prestige dalam permainan, dengan kata lain, merupakan pemain yang selalu ingin jadi yang terhebat dan tekuat.

b. Socializer, merupakan jenis pemain yang hanya ingin menambah teman, sering aktif pada chat room umum, jenis ini biasanya memilii banyak kawan dan mudah diterima oleh siapapun.

c. Killer, merupakan jenis pemain yang senang mengganggu dan membuat susah pemain lain dengan membunuh karakter pemain lain, merampas item pemain lain, 
merampok item pemain lain, dan lain sebagainya, dan hal tersebut menjadi suatu kesenangan bagi pemain jenis ini

d. Explorer, merupakan jenis pemain yang senang melakuakan penjelajahan atau eksplorasi baik terhadap peraturan, fasilitas, maupun peta yang ada dalam permaian tersebut, jenis ini adalah jenis pemain yang senang mempelajari kemampuan dari permainan, serta mendapatkan informasi - informasi mengenai permainan yang tidak disebutkan dalam tutorial permainan. (Yee ; 2014:29)

Pada kenyataannya, apa yang diulas Bartel tersebut memang terjadi di dalam Game Online, Salah satunya adalah Super Armada Online, yang merupakan sebuah permainan online produksi efun company limited, dengan jenis permainan strategi perang.

Perbedaan jenis pemain tersebut, sering menimbulkan konflik antar pemain, bahkan hingga terjadi perkelahian fisik di dunia nyata seperti yang terjadi di Thailand pada tahun 2013 , terjadi sebuah perkelahian akibat game online (https://www.youtube.com/watch?v=xcZJOW wir3A, diakses pada tanggal 03 Juni 2016, jam 17.57 WIB) .

Sementara untuk di dalam Game Super Armada Online yang peneliti teliti, hingga saat ini konflik masih terbatas di dalam lingkup dunia game tersebut.

Konflik yang terjadi baik di dalam Game Online, hingga yang sampai dibawa ke dunia nyata, merupakan akibat dari keinginan masing - masing pemain untuk dihargai , dihormati atau dikenal oleh pemain lain dalam sebuah permainan, dan keinginan masing masing pemain tersebut saling berbenturan satu dengan yang lain.

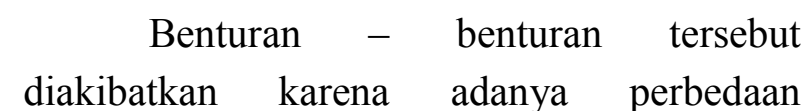
motivasi yang menjadi latar belakangnya. Seperti yang diulas oleh Yee dalam , bahwa ada 5 (lima) faktor yang menjadi motivasi bagi pemain game online dalam mempresentasikan diri, yaitu:

a. Relationship, terkait dengan kinginan untuk berinteraksi dan membentuk hubungan yang berarti

b. Manipulation, ingin memanfaatkan pemain lain untuk kepentingan dan kesenangan diri sendiri

c. Immersion, dengan berada di dunia fantasi atau hayalan, berarti menjadi orang lain, berbeda dengan karakter asli di dunia nyata.

d. Escapism, menjadikan dunia fantasi tersebut sebagai tempat untuk melarikan diri sementara waktu dari segala permasalahan di dunia nyata

e. Achievement,menjadi yang paling hebat dan kuat di dalam lingkungan virtual tersebut (Bainbridge;2010:49)

Dari pemaparan di atas, terlihat adanya kesenjangan di antara pemain Super Armada Online, yang terjadi akibat perbedaan cara masing - masing pemain dalam mendapatkan pengakuan dari pemain yang lain dalam permainan ini.

Perbedaan cara masing - masing pemain (orang) dalam mendapatkan pengakuan dari pemain (orang lain) ini disebut sebagi Face Work ( Ting-Toomey; 1999:36)

Berdasarkan permasalahan tersebut, maka tujuan penelitian ini adalah: untuk mengetahui bagaimana Online Gamers melakukan Face Work dalam Game Online Super Armada Server Atlantis dan mengapa mereka melakukan Face Work tersebut.

Kajian empirik hasil penelitian sebelumnya adalah penelitian dari Liam 
Bullingham dan Ana C. Vasconcelos, yang berjudul "The presentation of self in the online world': Goffman and the study of online identities". Peneliti membahas mengenai Erving Goffman face work dalam kehidupan di dunia online, dan aplikasinya dalam analisis identitas dan presentasi diri dalam kehidupan di dunia kedua, dalam hal ini dunia online. (Bullingham \&Vasconcelos : 2013)

Tujuan dari penelitian tersebut adalah untuk mengetahui bagaimana Erving Goffman Face Work diterapkan dalam identitas dan interaksi dalam dunia online. Selain itu, penelitian tersebut juga bertujuan bagaimana presentasi diri dilakukan oleh seseorang dalam beraktifitas dalam dunia online.

Perbedaan anatara penelitain ini dengan penelitian sebelumnya yaitu, dalam penelitian sebelumnya, peneliti melaukan penelitian terhadap pengguna blog, atau yang sering disebut dengan blogger, sementara dalam penelitian ini, peneliti lebih fokus kepada pemain game online, atau yang biasa disebut Online Gamers. Kajian empirik kedua adalah hasil penelitian dari Marie L. Radford, Gary P. Radford, Lynn Silipigni Connaway, dan Jocelyn A. DeAngelis mengenai "On Virtual Face-Work: An Ethnography Of Communication Approach To A Live Chat Reerence Interaction", penelitian ini bertujuan untuk menganalisa face work dalam text di chatting room antara petugas perpustakaan dengan pengguna perpustakaan. ( Radford, Conway \& DeAngelis ; 2011)

Tujuan penelitian tersebut adalah bagaimana Face Work dilihat melaui pendekatan etnografi komunikasi dalam melakukan interaksi melalui dunia virtual.

Perbedaan dengan penelitian ini adalah bagaimana Face Work terjadi dalam dunia Virtual Super Armada Online Game diantara para pemainnya, melalui pendekatan Autoetnografi.

Teori - teori yang digunakan untuk melakukan analisis face work Online Gamer Super Armada dari cara masing - masing pemain dalam mendapatkan pengakuan dari pemain lainnya, yaitu menggunakan teori Face Work.

Menurut Erving Goffman, Face Work adalah, memberikan wajah (Face) sebagai cara agar orang lain dapat memahami lebih baik apa yang ingin dipresentasikan, ini adalah cara untuk mendapatkan wajah (Face)( Goffman; 1967:9)

Stella Ting Toomy, menyatakan bahwa Face Work merupakan suatu sikap tertentu dalam berkomunikasi yang bertujuan untuk menyelamatkan wajah sendiri atau orang lain. Wajah dalam hal ini dapat diartikan sebagai harga diri, kehormatan, martabat, dan manusia sering melakukan Face Work dengan cara - cara yang kreatif guna menyelamatkan harga dir dan kehormatannya. ( Ting-Toomey; 1999:37)

Fungsi wajah menurut Goffman adalah untuk memberikan performa dan menunjukan keuntungan apa yang didapat oleh orang lain, yang kemudian akan menumbuhkan kepercayaan dan kesadaran diri, dalam impresi realitas, dimana individu tersebut menemukan siapa dirinya (Goffman;1957:10)"

Te-Stop Lim dan John Bowers dalam West and Turner menyatakan bahwa dalam face work, terdapat 3 (tiga) bentuk face work, yang terkait satu sama lain, ketiga nya adalah:

a. Facework ketimbangrasaan (tact facework), biasa disebut sebagai kepekaan dalam memberi kebebasan kepada seseorang untuk bertindak dan berekspresi seperti yang orang tersebut inginkan, sekaligus menekan hal - hal yang mengekang kebebasan tersebut. 
b. Facework Solidaritas (Solidarity Facework), jenis facework yang berkaitan dengan penerimaan atas orang lain dalam kelompok. Solidaritas dapat meningkatkan hubungan antar individu, dengan meminimalkan perbedaan melalui bahasa informal dan berbagi pengalaman

c. Facework Keperkenaan (Approbation Facework). Bentuk faceworkyang focus pada meminimalisir hal - hal jelek dari seseorang, dan memaksimalkan hal - hal positif dari seseorang.

(West \& Turner;2010 : 452)

Ketiga jenis Face Work tersebut merupakan tiga hal yang berbeda namun merupakan satu kesatuan yang saling terkait satu dengan yang lain.

Menurut Brown \& Levinson dalam West \& Turner, di dalam Face Work, terdapat teori kesopanan, yang menyatakan bahwa manusia akan melakukan strategi kesopanan berdasarkan ancaman yang dihadapinya. Dalam diri manusia terdapat 2 (dua) macam wajah (Face) yaitu Positive Face yaitu keinginan seseorang untuk disukai dan diterima orang lain dan Negative Face, yaitu keinginan seseorang untuk diakui keberadaannya oleh orang lain (West \& Turner;2010 : 451)

\section{METODE}

Penelitian ini merupakan penelitian kualitatif, yang secara ontology merupakan bentuk constructivisme atas realitas, secara epistemology bersifat interpretatif, secara aksiologi tidak bebas nilai atau subjektif dan secara metodologi bersifat Hermeneutical. (Denzin \& Lincoln; 2005 : 195)

Penelitian ini menggunakan metode Autoetnography, yang menawarkan nuansa, kompleksitas dan pengetahuan spesifik mengenai kehidupan, pengalaman dan hubungan tertentu, dibandingkan dengan informasi umum mengenai sekelompok besar orang.

Fokus dalam metode penelitian ini adalah:

- Mengenali batas dari pengetahuan ilmiah, dalam hal identitas, kehidupan, hubungan dan membuat nuansa yang kompleks serta spesifik atas pengalaman budaya atau seseorang

- Menghubungkan pengalaman pandangan dan pengalaman dari dalam diri sendiri dengan percakapan, konteks dan kaidah yang lebih luas dari hubungan, budaya dan politik

- Menjawab dengan narasi dan bercerita serta menempatkan secara seimbang pengetahuan dan nilai seni yang penting.

- Mengikuti implikasi dari kinerja mereka untuk, partisipan, audiens dan diri mereka sendiri. (Adam,Jones \& Ellis ;2015 :2125)

Operasionalisasi dalam

Autoetnography:

- memulai penelitian dengan menentukan tema penelitian yang hendak di teliti.

- Setelah menemukan tema, peneliti muali menggali informasi dari dalam diri mengenai hal yang ingin dipahami dan dimaknai lebih jauh dan mendalam, dengan bertanya kepada diri sendiri seperti apa yang membuat saya tertarik, apa yang ingin saya pahami lebih lanjut ,dan lain sebagainya.

- Memperbanyak informasi dengan melakukan komunikasi kepada orang lain dengan cara membuat kontak, melakukan diskusi, mengamati perilaku orang lain, serta wawancara, terkait permasalahan yang diteliti, untuk mengurangi kesenjangan informasi yang didapat dari pengalaman pribadi. 
- Untuk mengurangi kesenjangan informasi, peneliti juga harus menambah informasi melalui literatur - literatur yang terkait dengan permasalahan yang hendak diteliti, seperti foto, tulisan, dan lain sebagainya,

- Dalam Autoetnografi, seorang peneliti harus mampu menyampaikan hal hal yang sesuai dan terkait dengan kajian dalam penelitian, dan tidak terbawa oleh emosi, serta mampu memilah informasi yang layak di publikasikan, dan informasi yang berada di dalam wilayah pribadi, unttuk menjaga hubungan dengan orang atau pihak yang terkait dalam penelitian ini.

- Peneliti menafsirkan hasil dari penelitian yang dibuat dalam bentuk narasi yang menceritakan mengenai budaya dalam suatu hubungan di masa lalu dan saat ini dari peneliti sebagai manusia dan peneliti. (Adam,Jones \& Ellis ;2015:46 - 67)

Dalam autoetnografi terdapat beberapa prioritas, ketertarikan dan cara melakukan riset, yang terdiri dari:

- Berdasarkan pengalaman pribadi $\mathrm{dlm}$ penelitian dan penelitian

- Memberi ilustarsi dan sensasi proses pembuatan

- Menggunakan dan menampilkan cermin diri

- Menggambarkan pengalaman pribadi dari fenomena budaya

- Menggambarkan dan mengkritisi norma, pegalaman dan praktik dalam budaya

- Mencari respon dari audiens(Adam,Jones \& Ellis ;2015 :26)

Berdasar penjelasan di atas, Informan dalam penelitian ini adalah peneliti itu sendiri, dan peneliti harus mampu menceritakan pengalaman pribadinya secara seimbang antara pengalaman dan keilmuan, serta mampu member ilustarsi serta narasi yang membuat audiens terbawa dalam alur narasi penelitian ini.

Data - data penunjang dikumpulkan melalui observasi lapangan, serta mengumpulkan literatur - literatur ilmiah yang menunjang penelitian ini.

\section{HASIL PENELITIAN}

Dalam penelitian ini, informasi utama bersumber dari pengalaman peneliti ketika melakukan Face Work sebagai salah satu pemain dalam Super Armada Online Game, server Atlantis.

Berdasarkan pemahaman atas prinsip "memberikan wajah" dari Goffman(Goffman; 1967:9), Face Work yang dilakukan oleh peneliti di dalam Super Armada Online Game ini adalah dengan bersikap sebagai seseorang yang mudah bergaul, senang bercanda, tidak mudah terpancing emosi,suka iseng, senang melakukan kekonyolan dalam berinteraksi dengan pemain lain melalui chat room dalam permainan, baik world, clan maupun private chat.

Sebagai penunjang dari impresi diri peneliti di dalam Super Armada Online Game tersebut, peneliti menggunakan nama dengan konotasi yang menggambarkan karakter peneliti, yaitu dengan menggunakan nama "Semproelll" agar peneliti mudah diterima oleh para pemain lain dalam lingkungan virtual tersebut karena dianggap sebagai orang yang tidak serius, dan senang bercanda.

Face Work yang digunakan oleh peneliti termasuk berbeda dengan para pemain lainnya, dari pengamatan peneliti, ada beberapa pemain yang berusaha menggunakan ancaman dengan menunjukan kemampuan financial, ada pula yang melakukan ancaman dengan menjadi pengacau, ada pula yang bernegosiasi dengan memberi informasi, penengah pertikaian bahkan tidak sedikit pemain yang berusaha untuk menggunakan 
gender sebagai facework, dalam hal ini pemain laki - laki berusaha menjadi perempuan dan begitu juga sebaliknya agar dapat diterima dan dihargai oleh pemain lainnya.

Sikap - sikap yang ditunjukan oleh peneliti dan para pemain Super Armada Online Game melalui avatar, nama dalam game, teks yang digunakan dalam berkomunikasi melalui chatting room, serta tingkah laku yang ditunjukkan pada saat bermain permainan tersebut, merupakan bentuk facework masing - masing pemain dengan tujuan agar mendapat pengakuan dari pemain lainnya

Begitu juga dengan peneliti, semua sikap dan perilaku yang dilakukan dan ditunjukan dalam permainan tersebut, merupakan usaha untuk dapat diterima oleh semua pemain.

Dalam permainan online, terdapat kelompok atau kumpulan dari beberapa pemain yang terikat dalam aturan tertentu dan memiliki system hiraki, kelompok ini biasa disebut Guild, Clan,Faction dan lain sebagainya.

Setiap kelompok memiliki aturan main masing - masing, yang mengatur , interaksi dalam kelompok, termasuk juga penerimaan anggota kelompok.

Hal ini membuat setiap pemain melakukan facework untuk menegosiasikan diri agar dapat diterima dan diakui oleh kelompok yang ingin diikuti.

Di samping aturan antar kelompok, terdapat aturan tidak tertulis untuk menghukum pemain yang menjadi seorang Spy (mata-mata), yaitu dengan mengucilkan pemain tersebut dan diserang secara terus menerus oleh semua pemain hingga pemain yang menjadi spy tersebut berhenti bermain, atau biasa disebut "pensiun".
Peraturan - peraturan tidak resmi dan tidak tertulis tersebut, sempat membuat peneliti sedikit kesulitan untuk dapat diterima oleh pemain lainnya, hal ini karena peneliti belum tahu banyak mengenai kebiasaan dan budaya yang ada di dalam server Atlantis dari game Super Armada ini.

Peneliti mulai dapat di terima ketika level peneliti sudah mulai lumayan tinggi dan dianggap sebagai pemain yang cukup kuat, juga karena peneliti tidak pernah marah dan sering mengajak bercanda para pemain yang sudah menyerang "Base" peneliti dalam game, berusaha untuk menanggapi komentar negative dengan tenang dan tidak emosi, serta member informasi bagi para pemain baru tanpa ikut campur dengan cara pemain baru tersebut membentuk dirinya dalam permainan ini.

Pada saat peneliti sudah diterima oleh beberapa kelompok yang dianggap kuat, ada seorang teman lama peneliti yang juga bermain di permainan ini meminta peneliti untuk menjadi spy dalam kelompok saingannya.

Peneliti yang sudah dikenal baik oleh para pemain, tidak mendapatkan kesulitan ketika hendak bergabung ke dalam kelompok yang di tuju.

Saat peneliti sudah tergabung dalam kelompok yang di tuju, peneliti tetap bersikap sewajarnya, yang suka bercanda, suka iseng, jahil, agar peneliti mendapatkan kepercayaan penuh dari seluruh anggota kelompok tersebut.

Pendekatan interpersonal dengan membuka percakapan melalui chat pribadi maupun kelompok, menggunakan bahasan ringan mempermudah peneliti peneliti untuk mendapatkan informasi mengenai strategi “perang” yang digunakan oleh kelompok ini. Informasi - informasi penting yang didapatkan, peneliti dokumentasikan 
informasi tersebut dengan melakukan screen capture untuk disampaikan kepada yang membutuhkan informasi tersebut melalui messenger secara pribadi di luar game, agar tidak ketahuan.

Sedangkan di dalam kelompok, peneliti bersikap pura - pura bodoh, jika terjadi kegaduhan dalam kelompok yang dimata - matai karena strategi mereka bocor pada pihak lawan.

Berusaha untuk selalu ikut membantu anggota kelompok yang diserang lawan, dengan ikut menyerang balik, sebagai bentuk solidaritas.

Dalam berkomunikasi di dalam game ini, peneliti sering mengalami kesulitan, hal ini disebabkan karena media penyampai pesan , dalam hal in chat room dalam game memiliki keterbatasan dalam jumlah karakter yang mampu disampaikan, serta banyak pemain yang mengunakan kosa kata "alay" dan bahasa daerah yang kurang dimengerti oleh peneliti, hal ini juga sering menimbulkan kesalah pahaman.

\section{PEMBAHASAN}

Dalam sebuah permainan online, setiap pemain melakukan interaksi dan komunikasi dengan sesame pemain menggunakan pesan verbal, berupa teks yang disampaikan melalui chat room, serta pesan non verbal berupa tindakan dalam permainan ketika memperlakukan pemain lain.

Peneliti melihat bahwa pemain dalam permainan online, menggunakan Face Work yang dilakukan dalam kegiatan komunikasi dan interaksi dalam Super Armada Online Game, dan oleh peneliti dikaitkan dengan Teori Face Work Erving Goffman, 3 (tiga) jenis Facework menurut Stella Ting - Toomy dan Teori kesopanan Brown \& Levinson.

Tindakan yang dilakukan dengan mendesain avatar, nama cara berkomunikasi dan berinteraksi dalam permainan Super Armada Online Game yang dilakukan oleh peneliti, merupakan implementasi dari Face Work Goffman yang menyatakan bahwa Face (wajah) yang ditampilkan seseorang bertujuan untuk mendapatkan penerimaan dari orang lain dan dengan seperti itu dapat mengetahui siapa dirinya yang sebenarnya (Goffman;1957:10).

Dalam berkomunikasi dan berinteraksi di dalam Super Armada Online Game, sikap untuk memberikan kebebasan bagi pemain lain dalam membentuk diri merupakan hal yang penting, karena dengan memberikan kebebasan tersebut, maka pemain tersebut akan merasa dihargai, dan yang memberikan kebebasan tersebut akan diterima oleh yang lain . hal ini disebabkan karena masing masing pemain mempunyai latar belakang social, budaya , ekonomi, religi dan ideology yang berbeda - beda, yang menyebabkan masing - masing pemain mempunyai karakter yang berbeda .

Dengan diterima oleh para pemain, maka untuk dapat bergabung kedalam suatu kelompok, yang dalam permainan ini disebut dengan "Clan", menjadi lebih mudah.

Dengan berperan sebagai Spy. Peneliti dituntut untuk dapat diterima dan dipercaya oleh kelompok yang hendak dimata - mati, di lain pihak, peneliti harus menjaga kepercayaan yang diberikan oleh pihak kawan dengan memberikan informasi yang penting dan akurat mengenai pergerakan dan strategi lawan.

Sebagai spy, peneliti juga harus mampu menunjukan sikap setia kawan kepada kelompok yang dimata-matai dengan ikut membantu apabila ada anggota kelompok tersebut yang diserang, hal ini bertujuan agar peneliti dapat dipercaya dan tidak dicurigai oleh kelompok tersebut, bahwa peneliti berperan sebagai spy dari lawan mereka. 
Dalam berkomunikasi di dalam game, terdapat banyak keterbatasan yang ditemui oleh peneliti, seperti keterbatasan jumlah katrakter huruf yang dapat ditulis dalam chat room, banyaknya pemain yang menggunakan bahasa alay, dan juga bahasa daerah yang peneliti kurang atau bahkan tidak paham artinya.

Untuk mengatasi keterbatasan tersebut dalam berkomunikasi, peneliti menggunakan kalimat yang singkat, nudah dimengerti, terkadang menggunakan emoticon agar pesan dari peneliti mudah dimengerti oleh pemain lainnya

Berdasarkan pembahasan di atas, peneliti mendapatkan fakta bahwa untuk berinteraksi di dalam sebuah permainan online, sadar atau tidak, para pemain menggunakan prinsip - prinsip Face Work dalam berinteraksi di dalam permainan tersebut.

Setiap pemain dalam permainan online, memilih peran masing - masing dan menggunakan face work yang sesuai dengan peran yang mereka inginkan dalam bermain, baik sebagai Achiver, Socializer, Killer maupun Explorer (Yee ; 2014:29).

Orang yang berperan sebagai Spy, harus mampu melakukan berbagai jenis Face Work dalam berinteraksi, agar dapat diterima dengan baik oleh pihak yang berseberangan maupun yang sepaham.

Seorang Spy, juga harus mampu untuk menyembunyikan identitas dan keberpihakannya kepada hampir semua pemain, kecuali beberapa orang yang memintanya untuk menjadi spy.

Dengan kata lain seorang Spy harus mampu memanipulasi lingkungan,dalam hal ini memanipulasi pesan baik verbal maupun non verbal yang disampiakan melalui Chat Room dan tindakan dalam permainan, dengan memanfaatkan semua jenis Face Work dalam mencapai tujuan untuk mendapatkan informasi dan menghancurkan pihak yang dianggap sebagai lawan dari dalam kelompok tersebut.

Seorang Spy dalam melakukan perannya, menggunakan Positive Politness baik kepada pihak lawan maupun kawan, serta menggunakan Negative Politness terhadap pihak kawan, untuk mendapat kepercayaan dari lawan.

\section{KESIMPULAN}

Face Work, yang dilakukan di dalam permainan online, yang dilakukan oleh pemain, bertujuan untuk mendapatkan simpati dan penerimaan dari para pemain lainnya, sekaligus untuk mendapatkan pengkuan dari pemain lain. Ini biasa dilakukan oleh pemain dengan jenis Achiver, Socializer, dan Explorer

Untuk pemain dengan karakter Killer, akan menggunakan Face Work yang lebih cenderung kepada Negative Politnes, hal ini karena para pemain dengan karakter Killer, berusaha untuk menjadi yang paling unggul, dan sering kali untuk melakukan hal tersebut, para pemain melakukan threat atau ancaman atas Face (wajah) pemain lainnya, agar mendapatkan pengakuan, hal ini dibuktikan dengan sering terjadi konflik antar pemain yang dapat dilihat dari teks pada chatt room, serta tindakan pemain yang menyerang karakter online pemain lain dalam permainan secra terus menerus.

Di luar keempat jenis karakter yang dilakukan oleh para pemain seperti tersebut di atas, masih terdapat satu karakter yang belum disebut oleh Nick Yee dalam jurnalnya, yaitu Spy.

Spy merupakan karakter yang dibentuk untuk menjadi mata - mata yang disusupkan ke dalam kelompok lawan.

Seorang Spy harus mampu menyembunyikan identitas dirinya, dan 
memainkan berbagai Face Work dalam mencapai tujuannya. Seorang Spy mampu menggunakan Positive Politness untuk mencari informasi, dengan bersikap sopan, solider, dan humoris, yang bertujuan untuk mengacaukan bahkan menghancurkan lawan, serta menggunakan Negative Politness kepada kawan dengan merendahkan, bahkan membully untuk mendapatkan kepercayaan dari lawan.

Dengan kata lain, seorang spy harus mampu mengaburkan identitas dan keberpihakanya dengan cara memanipulasi pesan - pesan yang disampaikan melalui media Chat Room, dalam mencapai tujuannya.

Kesimpulan ini menunjukan bahwa, di dalam permainan online, Face Work sangat berperan dalam penerimaan dari lingkungan terhadap seorang pemain, untuk mencapai tujuan masing - masing, dengan melakukan manipulasi pesan dalam bentuk tulisan sebagai bentuk komunikasi verbal yang disampaikan kepada public melalui Chat Room serta tindakan yang diperbuat sebagai bentuk komunikasi non verbal dalam permainan Super Armada.

\section{Saran}

Bagi para peneliti yang tertarik dalam bidang komunikasi dalam dunia maya, baik media sosial maupun permainan online, perlu melakukan pemahaman atas teori - teori lainnya, serta melakukan penelitian menggunakan multi perspektif.

\section{DAFTAR PUSTAKA}

\section{$\underline{\text { Buku }}$}

Adams ,Tony E. Jones ,Stacy Holman, Ellis, Carolyn

AUTOETHNOGRAPHY, New York: OXFORD University Press
Bainbridge, William Sims Marchionini, Gary. (2010) Online Multiplayer Games, Chapel Hill: Morgan \& Claypool Publishers

Goffman, Erving (1967) Interaction Ritual Essays On Face-To-Face Behaviour. New York : Pantheon Books

Goffman, Erving (1957) The Presentation Of Self In Everyday Life. Edinburgh:Social Sciences Research Centre

Ting-Toomey,Stella. (1999) Communicating Across Cultures. New York: The Guilford Press

Yee, Nick. (2014) The Proteus Paradox How Online Games And Virtual Worlds Change Us-And How They Don't, New Haven \&London : Yale University Press books

West,Richard\& Turner ,Lynn H(2010) Introducing Communication Theory Analysis And Application, New York: McGraw-Hill Companies, Inc.

Denzin,Norman $\mathrm{K}$ \& Lincoln, Yvonna $\mathrm{S}$. (2005)The SAGE Handbook Of Qualitative Research (3rd ed). London :SAGE Publications

\section{Jurnal Ilmiah}

Bullingham, Liam and Vasconcelos Ana C.(2013) yang berjudul 'The presentation of self in the online world': Goffman and the study of online identities.United Kingdom: SAGE Publication .Inc

Radford, Marie L. Radford, Gary P. Connaway ,Lynn Silipigni \& DeAngelisl Jocelyn A. (2011) On Virtual Face-Work: An Ethnography Of Communication Approach To A Live Chat Reerence Interaction. Chicago:The University of Chicago. 


\section{Website}

Kurniawan, Derry.(2013, October 10) Janganlah Ditiru!!! Dampak Buruk Game Online.Akibat Masalah Sepele Di Dunia Game Menjadi Terjadinya Perkelahian.Youtube.com.diakses darihttps://www.youtube.com/watch?v $=$ xcZJOWwir3A pada tanggal 03 Juni 2016 ; Jam 17.57 WIB 